\title{
Preparing Preservice Teachers to Promote Mathematical Thinking in Infants, Toddlers, And Preschool- age Children
}

\author{
Jennifer Gilken \\ Jennifer Longley \\ Ruth Guirguis \\ Borough of Manhattan Community College, New York, United States
}

The Algebra for All (A4A) movement formally begins in 8th grade. However, algebraic thinking can be fostered in early childhood (EC). Yet, most EC teachers experience negative attitudes about math, which impacts how they facilitate mathematical learning in their students and student achievement. This exploratory project examined how curricular changes implemented during EC methods courses affected the math attitudes of community college EC preservice teachers (PSTs). The curricular changes included explicit, hands-on, and play-based pedagogical methods employed during curriculum courses to foster PSTs' capacity to facilitate pre-algebraic learning in infants, toddlers, and preschool-age children. PSTs completed a pre- and posttest math attitudes survey. Survey results were analyzed using a paired t test and multiple linear regression. Results were statistically significant. Implications for EC pedagogical and metacognitive instructional interventions are outlined.

Keywords: Teacher education, algebra, early childhood education, mathematical thinking

The skills needed to learn algebra begin with experiences and concepts introduced in early childhood (EC) education settings (Lee et al.; 2016; Taylor-Cox, 2003). The concepts that young children need in order to begin to think algebraically include numeracy, patterns, symbols, and understanding relationships between concrete materials; these concepts are developmentally appropriate for EC classrooms (Lee, et al., 2016), starting with infants (Geist, 2009). Young children's mathematical knowledge is influenced by environmental input (Baker, 2015; Klibanoff et al., 2006). In order to incorporate algebraic concepts into EC classrooms, EC teachers must be familiar and comfortable with these concepts and be able to create developmentally appropriate experiences for young children that support learning related to these concepts. However, many EC teachers do not feel 
confident and competent facilitating math due to their mathematical ability and confidence (Geist, 2015).

Preservice and inservice educators often have negative beliefs or attitudes about math (Gresham \& Burleigh, 2019; Jeffrey et al., 2018; White et al., 2005; Youmans et al., 2018) and experience math anxiety (Beilock et al., 2010; Fenty \& Anderson, 2014; Gresham \& Burleigh, 2019; Hollingsworth \& Knight-McKenna, 2018; Lake \& Kelly, 2014; Linder \& Simpson, 2018). A teacher's negative attitudes and beliefs about math impact willingness to learn math and comfort teaching math (Geist, 2015); their sense of self-efficacy (Jeffrey at al., 2018; Youmans et al., 2018); pedagogical practices (White et al., 2005); and student outcomes (Jeffrey et al, 2018; White et al., 2005; Youmans et al. 2018). Women and people of color may have limited opportunities to view themselves as competent in mathematics or to see others from their demographic background with advanced mathematics skills (Caessens, et al., 2009; Guitiérrez, 2018), which may contribute to perceptions of inadequacy in math. Reimagining math curriculum in EC teacher education programs could mitigate negative attitudes towards math and support more preservice teachers (PSTs) of color to join the teaching force. Thus, increasing PSTs comfort and competence with algebraic concepts, specifically EC teachers who will be working with infants, toddlers and preschoolers, is vital in undergraduate $\mathrm{EC}$ teacher education programs.

\section{Literature Review}

Infants, toddlers, and preschool-age children in educational programs should be immersed in rich mathematical learning opportunities. Infants are born with mathematical abilities, including spatial awareness, number sense (Chen et al., 2017) and the ability to remember patterns heard in utero (DeCasper \& Fifer 1980). Moreover, a foundational understanding of math has been identified as a predictor of later academic success (Chen et al., 2017; Duncan et al., 2007; Geist, 2011), which, in turn, can lead to potential higher earning future job opportunities. Consequently, it is imperative to develop (EC) teachers who are adequately prepared to facilitate mathematical thinking in infants, toddlers, and preschoolers.

\section{Math Skills in EC}

Young children have the capacity to engage in complex mathematical thinking (Fisher, et al., 2013; Presser, et al., 2015), yet most EC curriculum emphasizes the basic mathematic concept of numeracy (Hachey, 2013; Li et al., 2015; Linder \& Simpson, 2018; Powell \& Nurnberger-Haag, 2015), which is what EC teachers feel most comfortable teaching (Youmans et al., 2018). Complex mathematical concepts, such as algebra, are the least frequently covered in EC curriculum (Hachey, 2013) and infrequently studied (Linder \& Simpson, 2018), possibly because many EC teachers do not recognize that 
math learning starts at birth (Knasu, 2017). Taylor-Cox (2003) defines algebra in EC as generalizing mathematical concepts to solve problems with variables. Fostering algebraic thinking in infant-toddler classrooms promotes higher level cognitive skills, such as problem solving and reasoning.

A dearth of research exists related to mathematics with infants and toddlers in classroom settings (Linder \& Simpson, 2018). Infants, toddlers and preschoolers develop emergent mathematics conceptualizations as they make sense of relationships by interacting with teachers, develop understanding of attributes when participating in sensory play, and engage in mathematical conversations with teachers (Geist, 2009; Luckenbill, 2018). Thus, EC teachers should facilitate young children's learning through play and hands-on experiences that connect to their interests and allow for explorations (Hachey, 2013). In order for EC teachers to intentionally facilitate developmentally appropriate mathematical play, teachers must feel comfortable, competent with algebraic concepts and have positive math attitudes.

\section{Math Attitudes in EC teachers}

EC teachers require adequate training and preparation to feel confident and competent to facilitate mathematical learning with young children. Yet the opposite often occurs, as many EC teachers choose to teach young children because they intend to avoid mathematics in teaching (Beilock et al., 2010; Lake \& Kelly, 2014). This could be because most EC teachers are women and women tend to have less positive attitudes towards math (Beilock et al. 2010); prior experiences with math or in math classes (Linder \& Simpson, 2018), or lack of adequate training and preparation that many EC teachers have in EC mathematics (Linder \& Simpson, 2018; Youmans et al., 2018).

Attitudes are multifaceted, complex constructs that impact behavior (Ajzen, \& Fishbein, 2005). EC teachers' math attitudes impact their beliefs and knowledge about mathematics (Knaus, 2017; Theil, 2010). Negative attitudes towards math impacts EC teachers' confidence to teach math (Youmans et al., 2018). EC teachers' experiences with math shapes their attitudes towards math (Linder \& Simpson, 2018; White, et al., 2018) which impact their classroom practices and beliefs (Geist, 2015; White, et al., 2005). This, in turn, affects student beliefs, attitudes, and performance (White, et al., 2005). An EC teacher's negative attitudes towards mathematics can undermine their effectiveness and confidence causing students to develop negative attitudes towards math (Beilock et al., 2010; Youmans et al., 2005). EC teachers' and community college students enrolled in remedial math courses are reported to have similarly poor attitudes towards math (Reichwein, Zientek, et al., 2010). However, a small body of recent research -- much from outside of the US -has reported that EC teachers have more positive attitudes towards 
mathematics than originally thought (Anders \& Rossbach, 2014; Linder \& Simpson, 2018).

Constructivist (Gresham \& Burleigh, 2019) and play-based (SancarTokmak, 2015) teaching methods can positively change PSTs' math attitudes. Providing math activities and opportunities for EC PSTs to engage in may have a beneficial impact on teachers' confidence (Geist, 2015) and support the EC PSTs to feel more playful with math ideas which may allow them to be more open to math. Preparing PSTs to teach math to young children is a complex task that involves imparting the pedagogical skills to create learning experiences for young children, developing mathematical content knowledge, while addressing PSTs behaviors and attitudes.

\section{Theoretical Framework}

This research is based on multiple frameworks which serve as a reflection of the intricate and multifaceted nature of math in EC. These frameworks are National Association for the Education of Young Children (NAEYC), National Council of Teachers of Mathematics (NCTM), Algebra for All (A4A), and The California Way. NAEYC and NCTM (2010) emphasize the importance of a foundation in math that explicitly introduces mathematical concepts and language through appropriate, engaging, culturally and linguistically appropriate, meaningful experiences using high-quality methods. The joint position (NAEYC \& NCTM, 2010) statement recommends the use of teaching strategies that strengthen young learners' ability to problem-solve and develop reasoning processes that can be represented and communicated in a developmentally appropriate manner. The A4A initiative works to improve student readiness in algebra, educating teachers to be successful in teaching algebraic concepts to young learners and engage all students to strengthen abilities, while positively influencing their mindset (Choike, 2000). The California Way approach supports young learners to develop 21st-century skills such as critical thinking and problem solving (Furger, 2019). The aim is to foster these skills through a collaborative partnership among higher education programs and EC PSTs by facilitating the integration of algebraic concepts that are developmentally appropriate. The purpose of using multiple frameworks is to provide a holistic perspective to the mathematical challenges, barriers and inequalities that are faced by teachers, PSTs, teacher educators, and young children by providing educational advantages early on through changes in teacher preparation programs.

\section{Method}

This exploratory study examined how curriculum changes in one community college EC teacher preparation curriculum courses impacted the 
math attitudes of EC PSTs. The curriculum changes were two-fold and involved: 1) embedding the algebraic concepts of numeracy, patterns, symbols, and understanding relationships between concrete materials into the curriculum courses, and 2) using the pedagogical methods of explicit teaching, providing hands-on play-based activities, and analyzing play-based activities to embed the algebraic concepts into the course. Specifically, this research aimed to answer the following two questions: attitudes?

RQ1: How did the curriculum changes impact EC PSTs' math

RQ2: To what extent did the curriculum changes influence EC PSTs' math attitudes?

\section{Participants}

The participants in this study were a convenience sample of EC PSTs enrolled in a large, urban community college in the northeastern United States. Of the EC PSTs who participated in this project, $71.6 \%$ of students were identified as needing remedial support for math, yet only 54.2\% of EC PSTs successfully passed the remedial math courses, requiring additional math courses. Eighty-seven percent of the EC students identify as Black, Latinx, Asian, or Pacific Islander. The college's student body speaks 104 different languages and $71 \%$ percent of the college's students have an annual household income of less than $\$ 30,000$ (Borough of Manhattan Office of Institutional Research, 2018).

The 66 participants were enrolled in two specialized EC intermediate curriculum classes in the same EC program: an infant-toddler track or a preschool track. In both the courses, participants were exposed to algebraic concepts, unit planning, lesson planning, and integrating curriculum in infanttoddler/preschool classrooms.

\section{Materials}

The Student Math Attitude Survey (Korey, 2000) was abbreviated by the project funders for the purpose of math remediation research (Logue et al., 2016). The survey measures four factors:

1) Ability (students' perceptions of their mathematical ability),

2) Interest (students' interest in learning math),

3) Growth (students' belief that math will help them to grow), and

4) Utility (students' perceptions that math is useful in their future career and everyday use).

The modified Student Math Attitude Survey contained 17 items to measure perceptions of math attitudes of students using a Likert scale that ranges from 1) Strongly Agree to 7) Strongly Disagree (See Appendix). 
Bagley (2015) calculated Cronbach's alpha for the Math Attitudes Survey items, indicating good internal consistency $(\alpha=.89)$

\section{Procedures}

The research took place with two course sections of EC PSTs in fall 2019 and again with two different sections of EC PSTs in spring 2020. All of the EC PSTs enrolled in the course were invited to complete the Student Math Attitudes Survey on the first day of class each semester. Questionnaire completion was voluntary and anonymous. During weeks 4 and 5 of the semester, students were explicitly exposed to algebraic concepts in each age group through an instructor created PowerPoint presentation in class and provided with examples of the concepts in the context of EC routines, curriculum and play-based activities. EC PSTs had the opportunity to engage in hands-on and play-based activities for each of the concepts which enabled them to experience examples of the concepts in infant-toddler or preschool classrooms. As the semester progressed, additional opportunities for hands-on play-based learning were offered, PSTs were then asked to identify how the concepts of numeracy, patterns, symbols, and understanding relationships between concrete materials were represented in various activities typically found in infant-toddler or preschool classrooms (e.g., blocks, manipulatives, dramatic play, sensory activities, etc.).

Prior to implementing the study, the instructors met, shared, discussed, and coordinated the materials to present and curricular activities to ensure the concepts were presented consistently and in a manner that was developmentally appropriate for the age group which was the focus of each course.

At the conclusion of the semester students were invited, voluntarily and anonymously, to again complete the Students Math Attitudes Survey. Data was analyzed using SPSS. A paired $t$ test was used to assess math attitudes before and after instructors taught pre-algebraic concepts in both preschool and infant and toddler curriculum courses. A multiple linear regression was conducted to measure the extent that math attitudes and dispositions influenced perceived mathematical performance in PSTs after engaging in explicit instruction, hands-on and play-based activities and then analyzing play-based activities focused on algebraic concepts during an EC curriculum course.

\section{Results}

\section{Results for RQ1:}

The first research question investigated if there was a statistically significant difference in EC PSTs' math attitudes before and after explicit teaching on algebraic concepts and providing hands-on and play-based activities using the algebraic concepts of numeracy, patterns, symbols, and 
understanding relationships between concrete materials into EC curriculum classes. A paired $t$ test was used to assess math attitudes in both infant-toddler and preschool curriculum courses. As seen in table 1, the mean math attitudes score at the onset of the course, before the math intervention was $4.1(S D=$ 0.90 ) and the average math attitude score after taking the course was 3.8 ( $S D$ $=0.75$ ) indicating a mean difference of .6. EC PSTs had greater negative math attitudes before engaging in the math intervention of participating in the EC curriculum course that offered explicit instruction, hands-on and play-based activities and then analyzing the play-based activities focused on algebraic concepts. The mean difference between the scores was statistically significant $(t(65)=4.8, p<.01)$.

Table 1

Paired Samples T-Test Comparing Math Attitude Before and After PreAlgebraic Curricular Implementation $(\mathbf{N}=66)$

\begin{tabular}{lllllll}
\hline Pair & & \multicolumn{3}{c}{ S.E. } & & \\
& $M$ & $S D$ & Mean & $t$ & $d f$ & $p$ \\
\hline Pre-Test Math & 4.1 & 0.90 & 0.12 & 4.8 & 65 & .00 \\
Post-Test Math & 3.8 & 0.75 & 0.09 & & & \\
\hline
\end{tabular}

\section{Results for RQ2:}

The second question examined the extent that self-perceived mathematical ability influences math attitudes in EC PSTs after the implementation of algebraic concepts in both infant-toddler and preschool curriculum courses. To address this research question, a multiple linear regression was conducted. EC PSTs' perceived mathematical ability was entered as predictors in the model. A composite ability variable was created using similar constructs used in the Mathematics Math Survey Subscale (Korey, 2000) with a high reliability $(\alpha=.84)$. Prior to interpreting the regression model, Tolerance the Variance Inflation Factor was examined. Per Cohen, Aiken, and West (2004), the results indicated that multicollinearity was not an issue given that Tolerance values were above .10 and VIF values were less than 10 (see Table 2).

The model was statistically significant $\left(F(1,64)=79.39, p<.001, R^{2}\right.$ $=.55)$ and accounted for $55 \%$ of the variance in self-perceived mathematical ability after participating in the curriculum course that offered opportunities to explore algebraic content. The findings in Table 2 revealed that EC PSTs' self-perceived mathematical ability significantly predicted math attitudes $(\beta$ $=.94, p=.001)$. 


\section{Discussion}

This research revealed three significant findings related to math attitudes in EC PSTs. These results include: 1) self-perceived mathematical ability predicts math attitudes; 2) constructivist pedagogical strategies appear to reduce PSTs negative math attitudes; and 3) reduction of negative math attitudes and adequate preparation can potentially support EC PSTs to foster algebraic thinking in young children.

Table 2

Regression Coefficients for the Math Ability

\begin{tabular}{llllllll}
\hline Model & $B$ & Std. Error & $\beta$ & $t$ & $p$ & Tol. & VIF \\
\hline Math Ability & .94 & .11 & .74 & 8.9 & .001 & 1.0 & 1.0 \\
\hline
\end{tabular}

Note $. \mathrm{TOL}=$ tolerance, $\mathrm{VIF}=$ Variance Inflation Factor. Overall model $\left(F(1,64)=79.39, p=.001, R^{2}\right.$ $=.55$

Primarily, this study found that PSTs' self-perceived mathematical ability predicts their math interest, utility and growth attitudes according to the modified Math Attitudes Survey. Thus, one method to reduce EC PSTs' negative math attitudes is to increase their self-perceived mathematical ability. It is imperative to reduce PSTs' negative math attitudes because a teacher's math attitudes impact their instructional practices and student achievement (White et al., 2005; Youman et al., 2018). Addressing math attitudes during the preservice years can build EC teachers confidence and competence to teach math. Consequently, EC teacher educators must identify methods to reduce the negative math attitudes of community college EC PSTs to better prepare PSTs to facilitate mathematical thinking in infants, toddlers, and preschool age children.

Second, this project identified that when teacher educators use constructivist pedagogical strategies, it appeared to reduce the negative math attitudes of EC PSTs. EC PSTs reported more positive math attitudes when algebraic concepts were taught using explicit instruction combined with multiple opportunities for hands-on, play-based learning activities in EC curriculum courses. This study utilized sensory activities, such as engaging in sand and water play with containers and fingerpainting. EC PSTs were invited to reflect on the algebraic concepts young children could learn in such activities, how a teacher could facilitate the concepts, and take turns facilitating embedding algebraic concepts into the activities with their peers. Similarly, utilizing reform-based, constructivist methods (Gresham and Burleigh, 2019) and play-based approaches (Sancar-Tokmak, 2015) were 
effective in reducing negative math attitudes and increasing the teaching efficacy of EC PSTs

Third, this research suggests that reducing negative math attitudes and adequately preparing EC PSTs can enable EC PSTs to foster algebraic thinking in young children. Adequate preparation for EC PSTs involves both developing content knowledge on algebraic concepts in EC and the pedagogical skills to foster algebraic thinking in young children (Anders \& Rossbach, 2014). This requires bolstering positive attitudes towards algebra and PSTs' confidence as a person who can do math and facilitate mathematical learning in young children. Algebra has traditionally been viewed as a gateway for higher math and career opportunities (Choike, 2000). Algebraic thinking can promote 21st century skills in young children (Furger, 2019).

The results of this study suggest that by making algebraic concepts accessible for EC PSTs, when teacher educators use explicit algebraic concept instruction and multiple opportunities for hands-on play-based learning experiences coupled with opportunities to reflect on how to connect play to algebra, PSTs experience a positive change in their math attitudes. Consequently, PSTs may be less avoidant of math and open to develop the content knowledge and pedagogical skills to facilitate algebraic concepts with infants, toddlers, and preschool-age children. The current study contributes to the literature on preparing EC PSTs by: 1) identifying ways to predict PSTs math attitudes, and 2) identifying EC teacher education curriculum methods that positively changed PSTs attitudes towards math, and 3) identifying how to prepare EC PSTs who intend to work with infants, toddlers and preschools to facilitate algebraic concept development.

\section{Limitations}

Limitations exist relating to the methodology of the study. The first limitation relates to the convenience sample. Students included in this research were enrolled in curriculum classes at one community college. Additionally, the data collected was self-reported; self-reported data is based solely on the perception of participants. Students may not have attended class during the days of survey distribution or may have chosen not to participate in the study, which precludes the voices of all members from being included in the sample.

\section{Educational Implications and Future Research}

Currently, the literature examines the introduction of $\mathrm{A} 4 \mathrm{~A}$ in upper elementary and middle school grades. This research provides guidance for EC teacher educators to deepen their understanding of how to support EC PST's to introduce algebraic concepts to infants, toddlers and preschool aged children. 
Prior research has noted that EC teachers tend not to implement an intentional math curriculum that emphasizes complex mathematical skills because of their fear and anxiety about math (White et al., 2005; Youman et al, 2018) as well as or lack of knowledge and pedagogy in math (Hachey, 2013; Knaus, 2017; Li et al., 2015). Additionally, when EC teachers introduce mathematics into the EC curriculum it typically focuses mainly on the concept of numeracy (Hachey, 2013; Knaus, 2017) and does not capitalize on the complex mathematical capacity that young children possess. The negative mathematical attitudes teachers hold have the potential to be unintentionally transmitted to the children in their classrooms based on their behavior; this could perpetuate a cyclical process of negative attitudes (Beilock et al., 2010; White, 2005) towards math in the next generation of learners.

Supporting the development of mathematical knowledge and pedagogical skills in EC PSTs as well as mitigating negative math attitudes may impact their classroom practices when they are in-service teachers. This is significant because introducing algebra in the early years establishes the skills and mathematical underpinnings required for future math learning (Taylor-Cox, 2013), promotes 21st century skills (Furger, 2019), creates a gateway to higher paying career trajectories (Choike, 2000), can break the cycle of negative attitudes, and possibly bolsters math-esteem (a positive attitude about mathematical ability).

Algebra has traditionally been viewed as a gateway for higher math and career opportunities (Choike, 2000). Although research has typically focused on identifying negative math attitudes in EC PSTs, few studies have explored methodologies to prepare EC PSTs to embed algebraic concepts into their repertoire of teaching skills while addressing the issue of negative math attitudes. Previous research has called for more emphasis to be placed on mathematics development in teacher preparation programs (Knaus, 2017). Concurrently, this research addressed how to mitigate negative math attitudes in EC PSTs, community college PSTs, and PSTs who intend to work with infants and toddlers, as well as how to equip them with the ability to introduce algebraic concepts in EC classrooms.

\section{References}

Ajzen, I., \& Fishbein, M. (2005). The influence of attitudes on behavior. In D. Albarracín, B. T. Johnson, \& M. P. Zanna (Eds.), The handbook of attitudes (pp. 173-221). Mahwah, NJ: Erlbaum.

Anders, Y., \& Rossbach, H. G. (2015). Preschool teachers' sensitivity to mathematics in children's play: The influence of math-related school experiences, emotional attitudes, and pedagogical beliefs. Journal of Research in Childhood Education, 29(3), 305-322.

Baker, C. E. (2015). Does parent involvement and neighborhood quality matter for African American boys' kindergarten mathematics 
achievement? Early Education and Development, 26: 342-355. DOI: 10.1080/10409289.2015.968238

Beilock, S. L., Gunderson, E. A., Ramirez, G., \& Levine, S. C. (2010). Female teachers' math anxiety affects girls' math achievement. Proceedings of the National Academy of Sciences, 107(5), 1860-1863. https://www.pnas.org/content/pnas/107/5/1860.full.pdf

Borough of Manhattan Community College Office of Institutional Research and Assessment (2018). BMCC Fact Book.

Caessens, A., Duncan, G., \& Engel, M., (2009). Kindergarten skills and fifth grade achievement; Evidence from the ECLS-K. Economics of Education Review, 28, 4115-427.

Chen, J. Q., Hynes-Berry, M., Abel, B., Sims, C., \& Ginet, L. (2017). Nurturing Mathematical Thinkers from Birth: The Why, What, and How. Zero to Three, 37(5), 23.

Choike, J. (2000). Teaching strategies for algebra for all. The Mathematics Teacher, 93(7), 556-560.

DeCasper, A. J., \& Fifer, W. P. (1980). Of human bonding: Newborns prefer their mothers' voices. Science, 208(4448), 1174-1176. https://doi.org/10.1126/science.7375928

Duncan, G. J., Dowsett, C. J., Claessens, A., Magnuson, K., Huston, A. C., Klebanov, P., ... \& Japel, C. (2007). School readiness and later achievement. Developmental psychology, 43(6), 1428

Fenty, N. and Anderson E.M., (2014). Examining educators; knowledge beliefs and practices about using technology with young children. Journal of Early Childhood Teacher Education 35: 114-134.

Fisher, K. R, Hirsh-Pasek, K., Newcombe, N., \& Golinkoff, R. M. (2013). Taking shape: Supporting preschoolers' acquisition of geometric knowledge through guided play. Child Development, 84(6), 18721878. doi: 10.1111/cdev.12091.

Furger, R. C., Hernández, L. E., \& Darling-Hammond, L. (2019). The California Way: The Golden State's quest to build an equitable and excellent education system. Palo Alto, CA: Learning Policy Institute.

Geist, E. (2009). Infants and Toddlers Exploring Mathematics Young Children, 64(3) 39-42.

Gresham, G., \& Burleigh, C. (2019). Exploring early childhood preservice teachers' mathematics anxiety and mathematics efficacy beliefs. Teaching Education, 30(2), 217-241.

Guitiérrez, R. (2018). Introduction: The need to rehumanize mathematics. In I. Goffney, R. Guitiérrez \& M. Boston (Eds.) Annual Perspectives in Mathematics. The National Council of Teacher of Mathematics, Inc.

Hachey, A. C. (2013). Teachers' Beliefs Count: Teacher Beliefs and Practice in Early Childhood Mathematics Childhood Education (ECME). Dialog, 16(3), 77-85. 
Hollingsworth, H. L. \& Knight-McKenna, M. (2018). "I am now confident": Academic service-learning as a context for addressing math anxiety in preservice teachers. Journal of Early Childhood Teacher Education, 39(4), 312-327. https://doi.org/10.1080/10901027.2018.1514337

Karp, K., Caldwell, J., Bay-Williams, J. \& Zbiek, R.M. (2011). Developing Essential Understanding of Addition and Subtraction for Teaching Mathematics in Pre-K-Grade 2. Reston, VA: National Council of Teachers of Mathematics.

Knaus M. Supporting Early Mathematics Learning in Early Childhood Settings. Australasian Journal of Early Childhood. 2017;42(3):4-13. doi:10.23965/AJEC.42.3.01

Korey, J. (2000). DARTMOUTH COLLEGE MATHEMATICS ACROSS THE CURRICULUM EVALUATION SUMMARY: MATHEMATICS AND HUMANITIES COURSES March 2000. https://math.dartmouth.edu/ matc/Evaluation/humeval.pdf

Klibanoff, R.S., Levine, S.C., Huttenlocher, J.,Vasilyeva, M., \& Hedges, L.V. (2006). Preschool children's mathematical knowledge: the effect of teacher 'math talk'.Developmental Psychology, 42 (1), 59-69.

Lake, V. E., \& Kelly, L. (2014). Female preservice teachers and mathematics: Anxiety, beliefs, and stereotypes. Journal of Early Childhood Teacher Education, 35(3), 262-275.

Lee, J., Collins, D. \& Melton, J. (2016).What does algebra look like in early childhood? Childhood Education, 92(4)305-310, https://doi.org/10.1080/00094056.2016.1208009

Li, X., Chi, L., DeBey, M. \& Baroody, A. J. (2015). A study of early childhood mathematics teaching in the United States and China. Early Education and Development, 26, 450-478. DOI: 10.1080/10409289.2015.994464

Linder, S. M. \& Simpson, A. (2018). Towards an understanding of early childhood mathematics education: A systematic review of the literature focusing on practicing and prospective teachers. Contemporary Issues in Early Childhood, 19(3) 274-296. Doi.org/10.1177/1463949117719553

Logue, A. W., Watanabe-Rose, M., \& Douglas, D. (2016). Should Students Assessed as Needing Remedial Mathematics Take College-Level Quantitative Courses Instead? A Randomized Controlled Trial. Educational Evaluation and Policy Analysis, 38(3), 578-598 DOI: 10.3102/0162373716649056

NAEYC. 2010. "Early Childhood Mathematics: Promoting Good Beginnings." A joint position statement of NAEYC and the National Council of Teachers of Mathematics (NCTM). www.naeyc.org/files/naeyc/file/positions/psmath.pdf.

Parlakian, R. (2018). Rocking and rolling. Exploring math with infants and toddlers: The joys and benefits of math-based books and language. 
Retrieved from https://www.naeyc.org/resources/pubs/yc/jul2018/joysbenefits-math-based-books-language

Powell, S. R. \& Nurnberger-Haag, J. (2015). Everybody counts, but Usually Just to 10 ! A systematic analysis of number representations in children's books. Early Education and Development, 26, 377-398 DOI: 10.1080/10409289.2015.994466

Presser, A. L., Clements, M., Ginsburg, H., \& Ertle, B. (2015). Big math for little kids: The effectiveness of a preschool \& kindergarten mathematics curriculum. Early Education and Development, 26 (?) 399-426. DOI: 10.1080/10409289.2015.994451

Reichwein Zientek, L., Yetkiner, Z. E. \& Thompson, B. (2010). Characterizing the Mathematics Anxiety Literature Using Confidence Intervals as a Literature Review Mechanism. The Journal of Educational Research, 103(6), 424-438. https://doi.org/10.1080/00220670903383093

Sancar-Tokmak, H. (2015). The effect of curriculum-generated play instruction on the mathematics teaching efficacies of early childhood education pre-service teachers. European Early Childhood Education Research Journal, 23(1), 5-20.

Taylor-Cox , J. ( 2003 ). Algebra in the early years? Yes! Young Children , 58 ( 1 ), $14-2$.

White, A. L., Way, J., Perry, B., \& Southwell, B. (2005). Mathematical attitudes, beliefs and achievement in primary pre-service mathematics teacher education. Mathematics teacher education and development, 7 , 33-52.

Youmans, A., Coombs, A., \& Colgan, L. (2018). Early childhood educators' and teachers' early mathematics education knowledge, beliefs, and pedagogy. Canadian Journal of Education, 41(4), 1079-1104. 


\section{Appendix}

STUDENT MATH ATTITUDE SURVEY

Fill in one of the numbered bubbles according to the following:

(1)-Strongly Agree; (2)-Agree; (3)-Somewhat Agree; (4)-Neutral; (5)Somewhat Disagree; (6)-Disagree; (7)-Strongly Disagree

1. To understand math I sometimes think about my personal experiences.

2. I am good at math.

3. If I work at it, I can do well in math.

4. Math helps me understand the world around me.

5. I enjoy learning new things in math.

6. I have taken some math courses in high school and college that were taught in a very interesting way.

7. Many situations in the world around me can be modeled mathematically.

8. I often feel like I'm missing something important in math class.

9. I want to study more mathematics.

10. Working in groups helps me learn math.

11. I rarely encounter situations that are mathematical in nature outside of school.

12. I try to avoid courses that involve mathematics.

13. In mathematics you can be creative and discover things for yourself.

14. I'm never sure my answer is right until I'm given the solution.

15. Learning mathematics makes me nervous.

16. Mathematical thinking helps me make intelligent decisions about my life.

17. I don't need a good understanding of math to achieve my career goals.

Acknowledgements

This research was supported through the Algebra for All initiative at the City University of New York, funded by the New York City Mayor's Office.

\section{Corresponding Author:}

Jennifer Gilken, Ph.D.

Borough of Manhattan Community College

Teacher Education Department

Early Childhood Program

Associate Professor

New York City, NY 10007

347/756-8561

jgilken@bmcc.cuny.edu 